\title{
An Award to Nurture the Leaders: APSI-Raja Sabapathy Leadership Award (Supported by Dr. Somes Guha)
}

\author{
Dinesh Kadam ${ }^{1}$ \\ ${ }^{1}$ Department of Plastic and Reconstructive Surgery, A J Institute of \\ Medical Sciences and A J Hospital and Research Centre, Mangalore, \\ Karnataka, India
}

\begin{abstract}
Address for correspondence Dinesh Kadam, MS, DNB, MCh, Department of Plastic and Reconstructive Surgery, A I Institute of Medical Sciences and A J Hospital and Research Centre, Mangalore, Karnataka 575004, India (e-mail: drkadam@yahoo.co.in).
\end{abstract}

Indian J Plast Surg:2020;53:402-404

\author{
Abstract \\ Keywords \\ - leadership \\ - plastic surgery society \\ - Sushruta-Guha \\ Lecture \\ - Association of Plastic \\ Surgeons of India
}

Leadership for any professional society needs visionary leaders, who are adequately motivated to assume the role. The Association of Plastic Surgeons of India (APSI) has instituted APSI-Raja Sabapathy Leadership Award (supported by Dr. Somes Guha) in 2019 to identify and nurture members with the potential to take up the leadership for the association in the future. The author, a first recipient, reflects on this innovative step.

Generally, awards are conferred to individuals to recognize their lifetime accomplishments or contributions to a chosen field. However, the award instituted by the Association of Plastic surgeons of India (APSI) in the year 2019 is a distinct one. It intends to recognize an individual who has the potential to be a leader in the future and groom him/her further for the role. The award is to encourage the awardee to take up leadership positions in their place and field of work and in professional organizations at the regional and national levels.

\section{Visionaries}

The benefactor behind this visionary thinking is Dr. Somes Guha, a Life Member of APSI and an Honorary Member of BAPRAS, UK. He spent most of his professional life in the UK and the USA and currently lives in Virginia, the United States, after retirement. Apart from plastic surgery, Dr. Guha is a great lover of Indian history and works hard to unearth the glory of India's scientific past with credible research. Through the Guha family's generosity, he initiated the Sushruta-Guha Professorship in Plastic Surgery with The Royal College of Surgeons of Edinburgh. Started in 2012, eminent surgeons were chosen worldwide each year, and the awardee delivered the Sushruta-Guha Lecture at the Summer Meeting of the BAPRAS from 2013 to 2017 (-Fig. 1). From 2018, the Royal

published online

December 30, 2020
DOI https://doi.org/

$10.1055 / \mathrm{s}-0040-1722804$ ISSN 0970-0358.
College of Surgeons of Edinburgh conducts the lecture at the annual congress of the ICOPLAST.

When Prof. Guha desired to contribute to APSI, he endorsed the award after none other than the international luminary Dr. Raja Sabapathy, an example of exemplary leadership. Leading from the front, Dr. Sabapathy and his team have inspired plastic and trauma reconstructive surgeons across the globe. Coimbatore's one time small Ganga hospital is now a renowned medical institute, attracting hundreds of international trainees and scholars. Dr. Sabapathy, who presided over many associations, has brought several international collaborations and laurels. Honored with his name, The APSI-Raja Sabapathy Leadership Award (supported by Dr. Somes Guha) will be awarded every year to a member of APSI who has shown promise to take our specialty to greater heights. The award carries a cash prize of Rs 1 lakh and a medal, and the awardee is required to spend time with a mentor or take up a leadership course or an activity that will enhance his leadership skills. It is expected that the awardee will be proactive to take up a leadership role at the APSI.

\section{First Awardee}

I am privileged and humbled to be chosen as the first recipient of the APSI-Raja Sabapathy Leadership Award
(C) 2020. Association of Plastic Surgeons of India.

This is an open access article published by Thieme under the terms of the Creative Commons Attribution-NonDerivative-NonCommercial-License, permitting copying and reproduction so long as the original work is given appropriate credit. Contents may not be used for commercial purposes, or adapted, remixed, transformed or built upon. (https://creativecommons.org/licenses/by-nc-nd/4.0/).

Thieme Medical and Scientific Publishers Pvt. Ltd. A-12, 2nd Floor, Sector 2, Noida-201301 UP, India 
(supported by Dr. Somes Guha) in 2019. I took the opportunity to attend a short course for medical editors at Oxford in November 2019 to enhance my abilities as the editor of the Indian Journal of Plastic Surgery (IJPS) and help position our journal as one of the world's premier plastic surgery journals.

\section{The Oxford Course}

The short course for medical journal editors was organized by PSP Consulting, which is headed by Ms. Pippa Smart. The course has been run in England every year since 1996, and over time, the course has been revised to ensure it remains relevant to the changing world of medical publishing. The idea for the course came from Mr. Richard Smith, then editor of the BMJ, who asked Mr. Tim Albert Training to organize it. After many years of running the course successfully, in 2007, Mr. Albert handed over the course to Ms. Pippa Smart. Ms. Pippa is a publishing consultant with many years' experience of providing

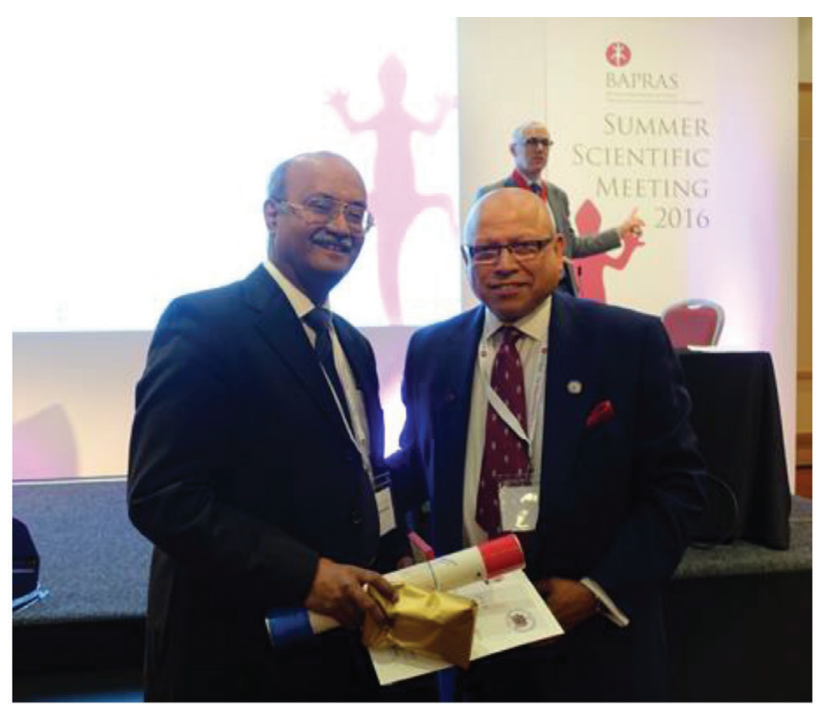

Fig. 1 Dr. Raja Sabapathy with Dr. Somes Guha after the presentation of the 2016 Sushruta-Guha Lecture at the Summer Meeting of the BAPRAS in Bristol. training to editors and publishing staff. She is also the editor of Learned Publishing, President of the European Association of Science Editors (EASE), and the invited Director of the World Association of Medical Editors (WAME). ${ }^{1}$

\section{Key Learning Points}

The Oxford course was a comprehensive and structured program for editors to guide and improve their journal from the basic functionality to update on various publishing requirements. It was an intense, interactive, and fruitful course with 26 editors from 14 countries representing medical journals of repute ( - Fig. 2 ). There was ample time for social interactions between the brainstorming sessions, including a short walking tour of Oxford. The key learning points were as follows:

1. Building the editorial team and the role of each one.

2. Scope of the journal and the readership.

3. Attracting good authors.

4. Guidelines for the peer review and authorship.

5. Dealing with plagiarism, fraud, conflicts, ethical issues, retractions/errata, etc., and avoiding them.

6. To understand the reader's behavior and effective delivery of key messages with graphics, lay summary, etc.

7. Improving visibility and marketing the journal with the help of social media and target-focused groups like conferences.

8. Enhancing the discoverability of an article with a relevant title and abstract in the manuscript.

9. Introduction to the podcast.

10. Vision on what to achieve in the next 5 years.

An editor's role demands enormous devotion of time with high output academic work in a stipulated time frame. Besides being responsible for the content, the editor leads the team, working along with coeditors, authors, reviewers, publishers/vendors, and monitoring quality metrics for comprehensive management. In our current model, the editor is also accountable for the finances of the

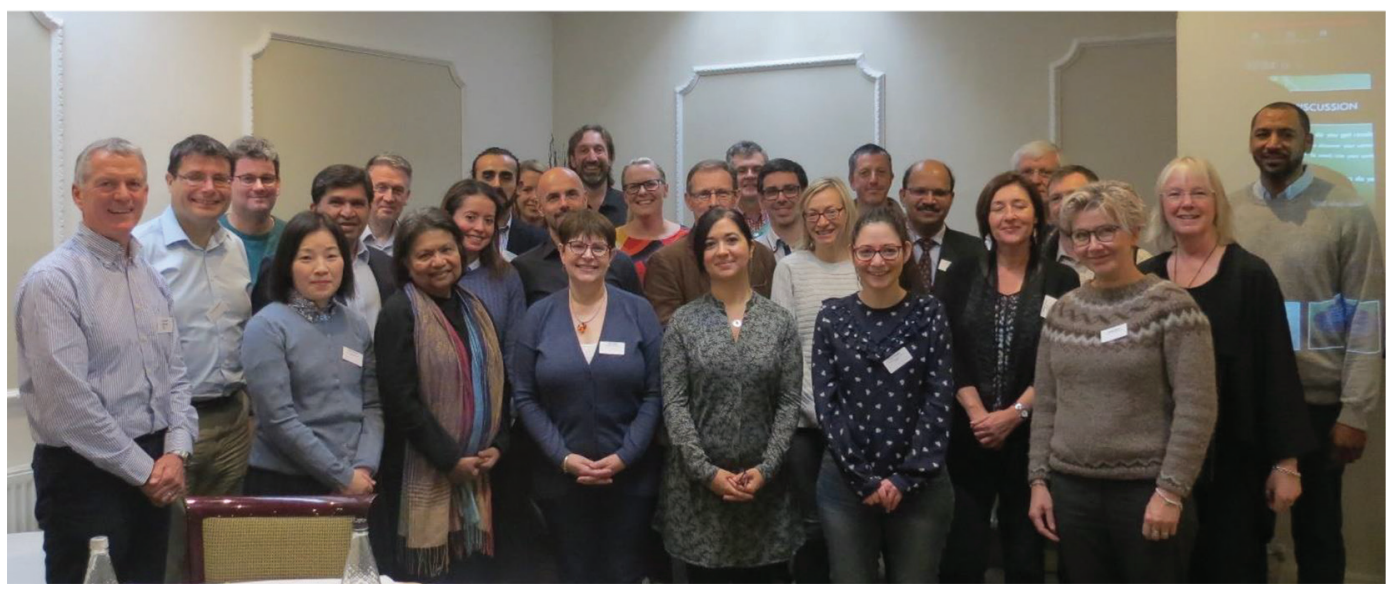

Fig. 2 Participants of the short course for medical editors at Oxford, 2019. (Pic. Courtesy: Ms. Pippa Smart, the course organizer, PSP Consulting). 
journal. In the absence of any formal training, such courses help the editor to understand the role and responsibilities and current guidelines to maximize the efficiency of the journal.

\section{India's Rise in Global Publications}

During the past 15 years, there has been an $11 \%$ increase in India's publications in all fields of science and engineering $(\mathrm{S} \& \mathrm{E}){ }^{2}$ With $4.8 \%$ of the global share, India stands among the top 5 countries with most publications next to China and the USA. Over $300 \%$ surge in medical science publication accounts for $15.3 \%$ of India's S\&E publications, which is still lower than the global average of $22.1 \%$. Further, India's output volume and international share of citations continue to increase. Despite this significant growth, the rising predatory publications, insufficient funding for quality research, lack of formative training to publish, and so on $^{3}$ seems to have eroded credibility in the scholarly environment.

\section{Our Mission}

Over the past 50 years, the IJPS has played a pivotal role in keeping the fraternity together, showcasing the country's scientific progress, and allowing international community participation. The IJPS continues to remain on the upswing on the author's preference and global readership amidst looming subspecialty publications. For our journal to attract well-researched, good quality articles from reputed authors, we need to emerge as a high-impact journal. This is possible only if we put up extraordinary efforts and team IJPS is working toward this mission. There is already a $200 \%$ increase in submissions from 37 different countries, amounting to $35 \%$ international contributions to IJPS. This progress is significant, an indicator of increased visibility and readership worldwide. With the change over of publisher to Thieme, e First articles are published ahead of print. Further, the articles appear in PubMed within a week of publication of the scheduled issue. As announced earlier, the IJPS will publish four regular issues from 2021 in addition to planned theme-based supplementary issues.

Our editorial team has expanded with the introduction of new associate editors. We have introduced resident associate editors in the team to provide postgraduates an opportunity to participate in the journal's editorial work and activities. They efficiently handle IJPS' social media pages on Facebook, Instagram, and Twitter, with a significant rise in the number of followers. With regular updates and highlights of interesting articles on social media, we aim to build awareness and readership of the journal.

The journal corpus is getting a much-needed boost from the APSI with Dr. Raja Sabapathy's request to utilize the bulk of APSICON 2011's savings of his presidential year. The editorial board of IJPS acknowledges this with gratitude.

\section{Our Vision}

Our vision for the next 3 years is ambitious but achievable. Getting impact factors remains high on the priority list. We are looking forward to collaborations with other international and subspecialty societies to be part of IJPS. Our vision is to enhance global networking and establish itself as a leading journal in the field.

I often remember Dr. Sabapathy's statement that leaders are crucial for any organized form of work execution, be it leading a professional organization like APSI, a team in sports, leading the country, or for that matter, even looting a bank! Leaders set the direction, build an inspiring vision, and help themselves and others to achieve the goal. An award like this will inspire and drive the recipient to take up the role and set a goal to achieve something new, which otherwise would not have been thought of and pursued.

\section{Declaration}

The author is the current editor of the IJPS.

\section{Conflicts of Interest}

None declared.

\section{References}

1 PSP Consulting. Available at: https://www.pspconsulting.org/ home/about-pippa-smart/. Accessed December 9, 2020

2 National Science Foundation. Available at: https://www.nsf. gov/statistics/2018/nsb20181/report/sections/academicresearch-and-development/outputs-of-s-e-research-publications. Accessed November 8, 2020

3 Hegde A, Patil N. Predatory publishing in India: has the system failed us? N.Acta Neurochir (Wien). 2020 (e-pub ahead of print). doi:10.1007/s00701-020-04644-8. Online ahead of print 